\title{
The impact of population increase and urban migration on global sustainability and quality of life
}

\author{
J. A. Pobiner \\ JPC Planning + Urban Design, Dallas, Texas, USA
}

\begin{abstract}
Global population has steadily increased for the last 50 years and could reach 10 billion by 2030. The percentage of the world's population living in urban areas has concurrently increased, exceeding 50\% in 2008 and is projected by the United Nations to reach $75 \%$ by 2030 . This paper reports on the impact of urban migration in the context of global growth and how it is affected by five key components: Urban Form, Food, Energy, Water, and Transport. From analysis of historic precedents, direct observation of current industry practices, and professional global urban design experience, it is concluded that the practice of city planning and design must adopt the principles of High Resolution Development, using compact neighbourhoods as the basic module to compose cities. The "City of Tomorrow" will contain both historic and technologically advanced components, relating to citizens on a human-scale.

Keywords: city planning, urban design, prototyping, sustainability, population. growth, transport.
\end{abstract}

\section{Where we are headed}

Earth is getting more crowded. Despite the 1960'S zero population movement and China's One-Child Policy (1979 through today), global population growth has progressed unabated. In 2008, for the first time in known history, a majority of the world's population was located in urban areas (the United States Census Bureau defines an "urban area" as a city with 50,000 persons or greater [1].) This news was met with a modicum of interest by the news media, but it heralded a significant change in urban growth and human development. 
Table 1: $\quad$ Global and US population growth, 1950-2030 [2].

\begin{tabular}{|cccc|}
\hline $\begin{array}{c}\text { Data } \\
\text { Type }\end{array}$ & Year & $\begin{array}{c}\text { Global } \\
\text { Population [2] } \\
\text { (in millions) }\end{array}$ & $\begin{array}{c}\text { US } \\
\text { Population [3] } \\
\text { (in millions) }\end{array}$ \\
\hline & 1950 & 2500 & 150 \\
Census & 1960 & 3000 & 180 \\
Data & 1970 & 3700 & 203 \\
& 1990 & 4500 & 226 \\
& 2000 & 5300 & 248 \\
& 2010 & 6100 & 281 \\
\hline Population & 2020 & 8000 & 308 \\
Projections & 2030 & 9800 & 341 \\
\hline
\end{tabular}

As shown in Table 1, actual census data from both the United Nations and the United States Census Bureau shows continual growth in the post-World War II years from 1950 to 2010. Both project continued growth through at least 2030.

The most typical concern about population growth has centered on the absolute number of people, rather than their location. However, it is now clear that the majority of the future population will be located in urban areas which significantly influence how existing cities are designed and redeveloped.

In The Next 100 Million [4], it was reported that as the United States reaches 400 million people, there will be a demand for 30 billion square feet $(27.87$ billion square meters) of new construction including 70 million new residences. Two-thirds of American jobs will be located in cities that were not considered "urban” in 1950. While the 2007 Great Recession severely impacted certain building professions (architecture, construction, engineering, etc.), the demands associated with population growth are recession-resistant. The malaise of the economic downturn will have little impact on births, deaths, eating, and demands for housing, energy, and education. Population growth will drive the economic decisions of the next 20 years.

In parallel, the number of large cities will also increase. The number of cities with 1 million persons or more has increased from 83 cities in 1950 to 468 cities in 2000 - a $463.9 \%$ increase. By 2030, that number is projected to increase to over 750 cities, with at least 221 located in China [5].

The result is the creation of multi-nodal/multi-centric megapolitan areas regions in which a large city is surrounded by numerous smaller cities whose total population exceeds the core city and makes up the larger percentage of regional population. Examples of these are found today from Los Angeles (California) to Phoenix (Arizona) to Dallas-Fort Worth (Texas) and beyond.

So how exactly did we get to this point?

\section{How we got here}

Urban growth patterns have largely been the result of a series of unplanned events with unintended and unimagined consequences. In the absence of national 
comprehensive urban growth policies - with none present in the United States urban growth and development has continued without any overall policy or direction, with the exception of market-driven economic enrichment, strategic military decisions, or, periodically, by royal decree.

From the American perspective, the period between 1865 and 1961 contains key influencers of current urban form.

\subsection{Building technology advancements (1865-1916)}

The late 1800s were a difficult period for both the United States and Europe. The American Civil War (1861-65) was followed by a bleak economic period known as the Long Depression (1873-79), with a similar economic experience occurring in Europe at roughly the same time (1873-1896) [6]. Yet in the face of economic uncertainty, building technology made great strides.

Vertical structures of the period were restricted by the physical limitations of either wood-frame or stone construction. The development of steel framing, combined with mechanical elevators, allowed for much taller structures. Concurrently, the ability to manufacture large pane glass allowed more sunlight to penetrate building cores, thus allowing for deeper floorplates. As the United States emerged from the Long Depression, use of this new technology helped to rebuild Chicago after the Great Fire of 1871 . It also led to a new generation of new high-rise buildings in Lower Manhattan in the late 1800s and early 1900s.

Corporations and financial institutions used this technology to construct impressive high-rise edifices to proclaim their financial stability. One such building - the Bankers Trust and Equitable Building (the Equitable), located at 120 Broadway in New York City - opened in 1911 as the world's tallest building at that time (62 stories), built to announce the company's financial strength after their previous wooden-frame headquarters had burned in 1908. An impressive architectural statement that still stands today, the Equitable cast a 7-acre shadow on Lower Broadway, keeping it in perpetual darkness. This was such a divisive issue that even the most pro-business industry trade journal - New York's Real Estate Record \& Guide - published an editorial that accused the Equitable of the "wholesale theft of daylight" [7]. The Equitable was not the only high-rise in New York, but as the tallest, it easily invited criticism.

\subsection{Rise of development regulations (1916-1926)}

So polarizing was the Equitable building that New York City was compelled to take regulatory action to prevent further large buildings from impeding light and air circulation at the street level. The result was the New York City Zoning Ordinance (1916), the first such ordinance in the United States and a landmark regulatory tool that was also the first Form-Based Code, controlling the shape of a building rather than the use(s) inside. The 1916 Ordinance regulated building height and required setbacks as the structure rose, so that light penetration and air circulation at the street level would not be compromised. This resulted in the classic "tiered/wedding cake" architecture evident in buildings of the period. 
The New York City Zoning Ordinance did not address the uses contained within buildings - an issue that would be addressed six years later in Euclid, Ohio.

In 1922, Ambler Realty proposed to develop an industrial park on 68 acres (27.5 hectares) adjacent to a railroad line that separated the Village of Euclid and the City of Cleveland, Ohio. Ambler Realty proposed that industrial was the logical use of their property since the same use existed on the Cleveland side. The Village disagreed and opposed Ambler Realty's proposal.

Since Village leaders did not want Cleveland's land use pattern to govern development adjacent to their existing residential neighbourhoods, Euclid passed a new type of zoning ordinance in 1922, one that controlled Land Use not just building form. The Euclid Zoning Code horizontally segregated objectionable uses from sensitive ones through the designation of Zoning Districts. Ambler Realty sued the Village, claiming the new Code limited the value of their land, amounting to a violation of the developer's Constitutional Fourteenth Amendment rights (depriving liberty and property without due process).

A series of lower court decisions and appeals ensued and eventually the case was argued before the United States Supreme Court. In 1926 by a 6-to-3 vote, the Court upheld the Village's code as constitutional [8] and the Euclid Zoning Ordinance - also known as Cumulative Zoning and Euclidean Zoning - became the model for cities across the United States. Euclid mandated the practice of physically separating land-uses by type and activity and remains largely the basis for municipal zoning ordinances across the United States.

\subsection{The city beautiful and city practical movements (1893-1950)}

American cities of late 1800s and early 1900s could hardly be called beautiful or inspiring - they were dirty and unsanitary places with unpaved roads and dangerous neighbourhoods. Many immigrants longed for the inspiring and beautiful cities they had left behind. This was the beginning of the City Beautiful Movement.

Beautiful cities in Europe and Asia were easier to achieve because they were often the vision of one man or one ruling family. But building beautiful cities in the United States proved to be prohibitively expensive. The best-known attempt was the 1893 World's Fair in Chicago. Built at the height of an economic recession, the World's Fair built an impressive example of a beautiful city at the then-audacious cost of over \$24 million (over \$500 million in current dollars). Designed by Chicago architect Daniel Hudson Burnham, the White City, as it was called, exemplified the principles of scale, harmony and ensemble and attracted more than 27 million visitors during its six-month run. The White City was never designed as to be a permanent part of Chicago and before any attempts could be made to preserve it, the White City was destroyed by arson in 1894 .

In the early 1900s, a parallel movement was gaining favour. The City Practical Movement focused on engineering to provide reliable infrastructure, paved roads, and sanitary living conditions. Efficient and effective engineering defined urban form rather than architectural style or visual aesthetic. The City Practical Movement is often cited by critics as a key reason that today's American cities and suburbs are non-descript and interchangeable. 


\subsection{The Servicemen's Readjustment Act (1944)}

The United States enacted the Servicemen's Readjustment Act [9] to address the inequities of how World War I soldiers were treated upon their return. Also known as the G.I. Bill, it offered veterans from World War II (and later the Korean War) benefits and guarantees including low-interest mortgage loans. More than 7 million veterans qualified for such loans, creating an unprecedented demand for new home construction. The suburban subdivision was created.

By the early 1950s, suburbs were sprouting up and down the east coast of the United States. These contained new homes designed for mass delivery and affordability, not necessarily architectural beauty. These were relatively modest homes, an average size of 900 square feet (83.6 square meters), built on a small parcel of land 5000 square feet (464.5 square meters) or less. The G.I. Bill is often cited as the key factor in creating the Baby Boom - a period of unprecedented middle-class growth and expansion that lasted from 1946 to 1964. This set the pattern for suburban expansion that continues through today.

\subsection{The Federal Highway Act (1956)}

As Supreme Commander in World War II, General Dwight Eisenhower was impressed by Germany's Autobahn and Italy's Autostrada as a means to efficiently transport troops and equipment. Few American roads compared with this and none had the scope or reach of their European counterparts. General Eisenhower saw this lack of a national roadway network as a security and strategic weakness of the United States, especially after the difficulties he experienced as one of the leaders of the Transcontinental Motor Convoy exercise (1919) - a strategic test of moving men and equipment across the country that was hampered by unpaved roads and insufficient bridges.

As President (1953-1961), Eisenhower had the opportunity to create a great national transportation system that would be the American version of the Autobahn and Autostrada. In his first term as President, he signed the Interstate Highway Act [10] into law, creating the American interstate highway system.

The National Interstate Highway Defense System was designed to be a network of high-speed roadways designed to deploy troops and equipment nationwide while avoiding urban traffic congestion. Estimated to cost $\$ 25$ billion and be completed by 1968, portions of the system remain unbuilt or are currently still under construction. Total system cost has exceeded $\$ 250$ billion. Inadvertently, interstate highways actually fostered suburban expansion and attracted increased traffic congestion. Today, it seems folly to use an interstate highway to quickly deploy anything and avoid congestion and density.

\subsection{Technological advancements (1948-1958)}

Two scientific innovations unintentionally influenced future urban form and daily life. In 1948, researchers at Bell Laboratories (Murray Hill, New Jersey) developed the Transistor as an alternative to mechanical telephone switch gear, accelerating telephone connections and minimizing down-time for maintenance 
and replacement of network components. Bell researchers John Bardeen, Walter Brattain, and William Shockley did not imagine how their invention would create a new class of consumer and industrial products. So important was this invention that all three Bell researchers were awarded the 1956 Nobel Prize in Physics.

By 1958, researchers at Texas Instruments (Dallas, Texas) created the Integrated Circuit which greatly magnified computing power by combining multiple transistors in a single layer. This led to the proliferation of personal electronics now used daily by billions of people, from laptop computers to smartphones. Like the Bell researchers, lead Texas Instruments researcher Jack Kilby was also awarded the Nobel Prize in Physics (in 2000).

The work of the Bell and Texas Instruments researchers unintentionally changed the nature of cities at the micro-level. People, homes, cars, and buildings could perform more efficiently. Transportation systems could provide real-time information relating to accidents and congestion. None of this would have been possible without the transistor and integrated circuit.

\section{Reinventing the future}

The aforementioned events influenced urban development over the last century and a half - advanced construction, development regulations, concerns about aesthetics and efficiency, provision of widespread low-interest mortgage loans, extension of roadway accessibility, and proliferation of personal electronics and connected devices. Yet, the end result has not been the general improvement of the built environment - quite the contrary.

Cities across the globe have expanded in size and scope but have failed to improve on the urban condition. Traffic congestion has risen in parallel with new lane-miles of roadway construction. Overbuilding and suburban sprawl have contributed to the urban heat island effect, negatively impacting the environment and significantly contributing to climate change. It is hard to imagine how current urban development models could be considered sustainable in the longterm. In order to accommodate projected urban growth over the next twenty years, cities must alter their trajectory. We can no longer afford to develop cities as we have over the last 50 to 75 years.

Fortunately, there is still time to adopt new principles and practices to meet our collective evolving needs. This paper proposes five key components necessary to effectively reinvent the future.

\subsection{Urban form}

As evidenced by our oldest cities, mankind has an established history of building urban areas. The basic framework contains two parts - the public realm and private development (respectively called Res Publica and Res Economica by the Romans). The public realm provided the necessary structure for a city (roadways, parks, open space, plazas, schools and public buildings), allowing the private sector to develop homes and businesses that allowed the city to thrive. 
Cities have allowed the Res Economica components to become horizontally separated through unintended Euclidean regulatory segregation and divergent market forces. Formerly-vibrant urban neighbourhoods have been replaced by single-use developments, diminishing sense of place and increasing traffic.

A new urban prototype - High Resolution Development (HRD) - is proposed, one that is flexible enough to adapt globally to various cultures and terrains while promoting time-tested successful neighbourhood design practices.

HRD's guiding principles emphasize a variety of land uses, access modes, architecture, and choice within a small area - a 5-to-10 minute walking distance, roughly a 1250 to 2500 foot (381 to 762 meter) radius, which is a commonlyaccepted distance used by planners and designers to gauge walkability of a certain area (presuming relatively level terrain and moderate climate). Within this Walkshed context, HRD guiding principles can be summarized simply as 3/3/3: a minimum of 3 different land use types mixed both vertically and horizontally (to promote diversity); a minimum building height of 3 stories (to promote density); and a minimum of 3 distinct travel modes (to promote accessibility).

Applying 3/3/3 guidelines to existing developed areas, it can be determined if both historic and new urban development incorporate HRD principles. For example, New York's Chelsea and London's Kensington neighbourhoods, as well as new developments including CityPlace (West Palm Beach, Florida) and Roppongi Hills (Tokyo, Japan) pass the $3 / 3 / 3$ test. These are successful in terms of financial revenue, sustainability, and sense of place.

Conversely, many of new American "town centers" (or "lifestyle retail centers") do not qualify as HRDs or even as neighbourhoods. These would appropriately be characterized as Low Resolution Developments (LRDs), as they are single-use regional retail centers converted into outdoor environments with no significant mix of uses or modes, and composed primarily of low-scale buildings. Typical American suburbs are almost always characterized as LRDs, as they are principally single-use developments (almost exclusively singlefamily detached homes) designed primarily around automobile access. Even many examples of New Urbanism developments do not pass the criteria for HRD.

Internationally, the trend of developing "designer cities" does not guarantee HRD-quality development. One example is Dubai's Palm Jumeirah, a terraformed island containing principally upper-income residential uses. While an impressive engineering feat, it fails to create walkable, diverse, and vibrant neighbourhoods.

HRD guiding principles expand upon the practice creating walkable, diverse neighbourhoods - a basic tenet of urban places for centuries. The City of Tomorrow may adopt incorporate various and diverse architectural styles, but the relationship of uses and built spaces should adhere to the HRD principle of 3/3/3 in order to accommodate future growth in a sustainable manner. HRD principles may also be integrated into existing "standard" development ordinances for ease of implementation in established neighbourhoods experiencing the next generation of development. 


\subsection{Food}

Current food production practices are usually physically distant from the consumer (a Euclidean problem) and are relatively horizontal and low-scale. Relying on natural climate patterns, herbicides and pesticides, agricultural operations are highly susceptible to drought, flood, excessive heat/cold, and other weather challenges. Current agricultural production practices and per-acre yields must increase significantly in order to feed a planet of nearly 10 billion people.

Cities are now re-discovering the benefits of community gardens, bringing affordable produce closer to consumers. Community gardens are often developed on vacant lots or building rooftops. While this is a good start, urban agriculture must take the next step in order to be a vital part of the neighbourhood and the global food chain.

Sweden's Plantagon International AB began construction of a new urban vertical farm in early 2012. The International Centre of Excellence for Urban Agriculture (also known as the plantscraper) [11] in downtown Linkoping (southwest of Stockholm) is the first in the new generation of vertical urban farms that promise to provide a controlled growing climate to increase production yields and bring food sources closer to consumers.

Open space adds value to urban areas for aesthetic, recreational, and now food production values. The City of Tomorrow must embrace and encourage urban agriculture and open space as important components. Euclidean logic has pushed agriculture away from residential areas and urban cores, but some American cities - including Portland, Oregon, and Lancaster, Pennsylvania recognize the value of agriculture to the local economy and as a compatible use adjacent to residential neighbourhoods. Open space and urban agriculture are key components in creating a liveable environment which adds value and provides new sources of food for a growing planet and the City of Tomorrow.

\subsection{Energy}

Energy demands are increasing even faster than population growth. In 2013, the number of web-connected devices in the United States exceeded the population. But the reliance on technology also shifts and increases overall energy demands.

Every text message, voice mail message, and email is stored on a server in a data center somewhere. Data centers can vary in size from a small closet to several hundred acres, but each requires constant power both for servers and air conditioning. Low-power chips can help reduce overall energy demand but more is needed. Data centers can be location-agnostic, sited in remote climates to utilize cool outside air to replace the need for mechanical air conditioning. Google is considering locations in Sweden for such a data center.

Technologies also shift energy demand from one source to another. Switching to electric vehicles (EVs) shifts overall energy demand from gasoline to electricity, potentially overwhelming power generation capacity and distribution. University campuses that convert to wireless connectivity find that their power demands actually double or triple as more devices which need to connect and 
recharge. An unintended consequence is that the simple electrical outlet has become a significant form-giver in most public spaces, from airports to hotel lobbies.

To meet growing energy demands, buildings and neighbourhoods must locally generate some degree of energy through solar panels, wind turbines, or other technologies. This must be considered as important an urban infrastructural component as water and sanitary sewer service.

Fortunately, simple changes can significantly reduce energy demand. In the City of Tomorrow, a properly designed, walkable HRD neighbourhood can reduce the need to use an EV car every day. This simple mode conversion can have significant energy savings in reducing the need to recharge the vehicle.

\subsection{Water}

Simply stated, there is no substitute for water. It is the most vital component for human development. It can also be deadly.

Early human settlements often located near water sources for strategic value (economic, agricultural, military) as well as to serve basic human needs. These cities are now also susceptible to hurricanes, tidal waves, and rising sea levels. Hurricane Katrina (New Orleans, 2005) and “super storm” Sandy (New York/New Jersey, 2012) demonstrated the devastating power a storm can have on a modern metropolis.

Lack of water is also critical. A 10-year drought has gripped most of the central and southern United States with little relief in sight for the short term. No effective strategies exist for reducing drought conditions.

For the planet to accommodate cities of 7.5 billion people, water usage can become more efficient, but it can never go to zero. Since the mid-1980s, US residential water usage has decreased 30\% (from 100 gallons per person per day to 70). But it is equally important that non-residential uses become more efficient for all industries (including agriculture). Otherwise, there will be insufficient water supplies to service both future industries and human consumption.

It would not be unreasonable to project that the next major war will be fought over water. The City of Tomorrow must take water sources and availability into account, and design new technologies to provide clean, safe, potable water for residential and non-residential uses.

\subsection{Transport}

In 1896, architect Louis Sullivan's observed that “form follows function” [12]. However, today one would argue (as many have noted) that "form follows parking”. The proliferation of affordable personal transportation has made the car a significant but unintended urban form-giver.

Cities large and small are defined by an intricate network of highways, local streets, parking lots, and garages. Regardless of the number of roadway widenings or new alignments, traffic congestion seems to remain unabated. Building more roads has not reduced vehicular traffic congestion. In fact, some would argue that it has only made the problem worse. 
An emerging middle-class expands automobile ownership. It happened in the United States in the 1950s, in Mexico in the 1990s, and is currently happening in China where the China National Bureau of Statistics reported 2012 car ownership at over 65 million, a 25\% increase over the previous year. China's growing adoption of an auto-centric lifestyle can be seen in recent reports of massive traffic congestion, sometimes stretching for more than 100 miles (160.9 kilometers) and lasting for days. Automobile emissions contribute to China's increasingly poor urban air quality. Developments that mimic American middleclass suburbs, such as Beijing's Orange County, exacerbate the problem of autocentric commuting patterns, traffic congestion, and air pollution.

Zoning and development regulations also contribute to auto-centric design. A typical American zoning ordinance requires office developments to provide between 4 and 5 parking spaces for every 1000 square feet (92.9 square meters) of office space. The average parking space consumes 350 square feet (32.5 square meters, including drive aisles and landscaping). Therefore, the total space dedicated to parking in a typical office development exceeds leasable built space by $40 \%$ to $75 \%$. Banks that finance developments often increase this parking ratio to 5 to 7 spaces per 1000 square feet, further aggravating the problem. Parking ratios tend to be lower in dense urban environments, but the space dedicated to cars remains high, often exceeding total built occupied space.

Applying the HRD principles of 3/3/3 reduces the impact of automobiles. In Zurich (Switzerland), the Bahnhofstrasse - a 0.8 mile (1.25 kilometer) street linking the main train station with Lake Zurich - is one of the most affluent shopping streets in the world and home to numerous private banks and wealth management firms. Its access is limited to pedestrians, streetcars, and bicycles (HRD's three modes), with cars allowed only along adjacent blocks (a ferry at the southern terminus of the adds a fourth mode). Similar patterns are replicated throughout the urban core of Zurich, with small, diverse neighbourhoods connected by streetcars that minimize the need for daily car use. Relying on multiple transport modes has not diminished Zurich's economy or quality of life.

In dense urban environments, cars are often the most expensive and least efficient means of access. Walking remains the simplest, least costly, and most accessible, sustainable, and healthiest mode (age, health, and terrain may limit this mode for some). The City of Tomorrow must take this into account.

\section{Summary}

Throughout history, urban patterns have yielded sustainable forms for growth and development. But since the end of World War II, these forms have been unintentionally abrogated by the proliferation of high-speed roadways, personal automobiles, single-use developments, policies that artificially encourage unsustainable development patterns, and even personal electronics.

Historic precedents of horizontally and vertically mixed-use and walkable neighbourhoods can easily be adapted for the City of Tomorrow to accommodate the projected population growth. Many large cities (New York, London, and Zurich, etc.) can be described as a series of connected, diverse neighbourhoods. 
HRD's simple set of design principles (3/3/3) will yield a more sustainable urban form, and promote improved quality of life, economic opportunity, and diversity. HRD's guiding principles can easily be integrated into existing and future regulatory language, ensuring promotion of historically-proven urban patterns.

\section{References}

[1] United States Census Bureau, 2010 Census Urban and Rural Classification and Urban Area Criteria (http://www.census.gov/geo/reference/urbanrural-2010.html), Washington DC, retrieved January 2013.

[2] United Nations, Population Division of the Department of Economic and Social Affairs of the United Nations Secretariat, World Population Prospects, New York, November 2010.

[3] University of California at Los Angeles, United States Census Statistics and Information (http://guides.library.ucla.edu/content.php?pid=104346andsid $=10$ 27428), Los Angeles, California, retrieved February 2013.

[4] Nelson, A.C. and Lang, R.E., The Next 100 Million, Planning, American Planning Association, Washington DC, January 2007.

[5] Brinkhoff, T., Principal Agglomerations of the World (http://www.citypopulation.de), Berlin, retrieved December 2012.

[6] National Bureau of Economic Research, Business Cycle Expansions and Contractions (http://www.nber.org/cycles.html), Cambridge, Massachusetts, retrieved January 2013.

[7] Gray, C., 1915 Equitable Building Becomes a 1996 Landmark, New York Times, New York, 8 September 1996.

[8] United States Supreme Court, Ambler Realty v. The Village of Euclid, 275 U.S. 365, 1926.

[9] Public Law 78-346, Washington DC, 1944.

[10] Public Law 84-627, Washington DC, 1956.

[11] Plantagon International AB, http://plantagon.com, retrieved December 2012.

[12] Sullivan, L., The Tall Office Building Artistically Considered, Lippincott's Magazine, issue \#57, Philadelphia, Pennsylvania, March 1896. 